\title{
Promoting Remote and Virtual Labs in Portugal
}

\author{
http://dx.doi.org/10.3991/ijep.v3iS1.2399 \\ M.T. Restivo ${ }^{1}$ and A. Cardoso ${ }^{2}$ \\ ${ }^{1}$ University of Porto, Porto, Portugal \\ ${ }^{2}$ University of Coimbra, Coimbra, Portugal
}

\begin{abstract}
Experimental activities are essential and contribute definitely to prepare future engineers for solving practical problems and for consolidating theoretical understanding and volatile knowledge based on abstract concepts. They are also fundamental for training engineers and engineering scientists. And finally experimental activities need rigor and procedure methodology in order to be correctly used in validation of new theoretical results or predictions. Remote and virtual experiments, online labs, enlarge the world capabilities in experimental activities and contribute for collaborative work using emergent technologies, bringing together engineers, researchers and professionals from different areas. During last decade much interest has been generated around remote and virtual labs allowing students, technicians and engineers to interact with remote and virtual experiments in higher education, in lifelong professional development, in industrial training, in industrial activities or even in making available very sophisticated equipment or new resources for "digital divide". In an epoch of a strong students' mobility the European economic slowdown context will bring negative consequences. Remote and virtual experiments will be an interesting help to improve collaborative intercultural students activities. The European populations ageing continue to age to unprecedented levels. Later retirement brings new requirements in lifelong learning in order to upto-date professionals.
\end{abstract}

pt.lab2go, the Portuguese version of lab2go Web platform, is a consortium recently created for fostering the Portuguese potential in online labs.

Index Terms-Computer experiments, lab2go, online labs, remote and virtual labs.

\section{INTRODUCTION}

Experimental skills are crucial in science and in engineering. Therefore, the role of laboratory experiments is fundamental in engineering and science instruction. The use of Information Technologies (IT) enhances different possibilities and much interest has been generated around online labs, allowing students, technicians and engineers to interact with online experiments in higher education, in lifelong learning, in industrial training, in industrial activities or even in making available very sophisticated equipment or new resources for developing countries.

Development of experimental skills are also capital in science dissemination between young generations trying to foster their interest and motivation in following higher education areas, like those of sciences and technology where the number of future graduates needs urgent and significant increase in Europe for guarantying knowledge sustainability.
Also, in education field, and considering recommendations from Bologna process, the decrease of contact hours and the focus in student work by fostering him/her autonomy in the process of acquisition and development of new skills, competences and knowledge, the remote and virtual experiments bring additional importance to online experimentation in order to attenuate this tendency and to help the student centered activity [1].

Remote experimentation is yet an interesting resource for facing the present financial constrains in many places in the world, guarantying alternative resources for learning and training. European populations ageing is bringing new regulation in retirement processes and this brings new requirements in lifelong learning in order to up-to-date professionals.

Therefore, higher education in Portugal has to be aware, too, of the importance of resources offered by online labs in different contexts and in its role as instructional tools:

- At the education level relevance is given to the students' involvement with the reality they will find in everyday life as professionals, to attenuate the tendency in reducing students contact hours, to foster student center experimental tasks, to improve collaborative intercultural students activities [2-4], etc.;

- In industry, they can contribute for a costless approach in the candidates' selection, for training assembly tasks, for lifelong education [5-9];

- Although, the European population ageing will add new requirements in lifelong learning in order to upto-date professionals in the technological progress and knowledge for new challenges in their jobs [10];

- In the developing countries context, results of the GÉANT project [11] provide a powerful structure for sharing online labs, as has been the case of the MIT cooperation with iLabs in Africa, making resources available to that large fraction of the world population affected by the "digital divide";

- In providing access to highly sophisticated equipment [12];

- At the dissemination level, the real problem of today's deficit of youngsters in Science and Technology degrees may be helped by academy and industry initiatives [13-15].

The authors were involved in a project between 20102011, funded by the Calouste Gulbenkian Foundation, and have been the promoters of the Online Portuguese Consortium recently created based in the Portuguese version (pt.lab2go [16]) of the lab2go [17] platform, from the GOLC Consortium [18]. 


\section{EXPERIMENT@PORTUGAL FINAL RESUlTS}

Experiment@Portugal [19] was a one year project supported by the Calouste Gulbenkian Foundation. It has been the seminal contribution for the creation of the Portuguese Consortium of Online Labs, i.e., pt.lab2go. The Faculty of Engineering of University of Porto and the Faculty of Sciences and Technology of the University of Coimbra were the host institutions of this project.

Information about the project results is available at http://www.fe.up.pt/experimentaportugal, Fig.1, in Portuguese and English languages.

In 2012, this experiment@portugal Web site has been prepared for disseminating the Consortium pt.lab2go and its resources in Portuguese speaking countries.

Helping to consolidate the international ontology proposed by GOLC [20] the experiment@portugal Web page includes a level named Ontology where definitions are clarified by animations exemplifying different types of labs: remote, virtual and hybrid.

At Laboratories level, the Web page offers clips from different types of existent experiments in order to increase the visitors' interest. The goal is, in the future, to provide a multimedia gallery of different type of technologies, offering a first contact with many of the available resources.

At Partners level it is possible to get information about each Consortium partner and to have direct access to its online laboratories.

The project ended in November 2011 with the $1^{\text {st }}$ experiment@ International Conference, exp.at'11, hosted by the Calouste Gulbenkian Foundation (in archive at http://www.fe.up.pt/exp.at2011/) and the project main results are now broadcasted in diverse Portuguese and Brazilian Web pages. Some of the experiments are already in English language but work has to be done now to offer the English version of all experiments in the future.

\section{PT.LAB2GO}

The International Association for Online Engineering (IAOE) and the GOLC Consortium (Global Online Laboratory Consortium) made available to the project the use of the lab2go platform (http://www.lab2go.net), created in the Carinthia University of Applied Sciences, Austria, in order to produce its Portuguese version.

The Portuguese version is an image of the original platform, preserving all the original characteristics and properties, and is also supported by a search engine of the information associated to each RVL resource. Fig. 2

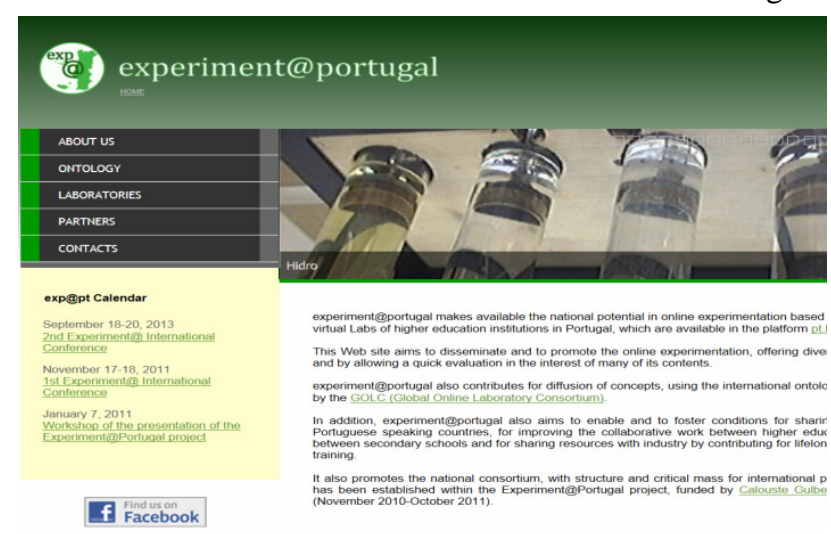

Figure 1. experiment@portugal Web page. shows a screenshot of the home Web page of the international pt.lab2go platform (http://pt.lab2go.net).

\section{A. How To Add New Contents To pt.lab2go}

With the current configuration of pt.lab2go, the addition of new contents is not carried out directly in the platform by the resource owners. The contributor should contact the platform administrator and fill a form with information about the resource.

To add a lab, it is necessary to define the following main parameters: label; lab type (hybrid, remote, virtual or online); general data (description, URL, ...); experiments included in the lab; specific properties (owners, requirements, technical data, ...).

To add a new experiment, the most important parameters are the following: label; type of experiment (fixed, observable or adaptable); general data (description, URL, ...); laboratory; educational properties (scientific field, educational level, ...).

\section{B. Examples}

The pt.lab2go was established with seven Portuguese partners. It offers 13 labs and 49 online experiments and is open to any newcomer. Some of the experiments are already in English but it will be important to get all in lingua franca in the near future.

The resources either of remote or virtual type (or even hybrid) are from different areas, covering physics, mechatronics, electronics, chemistry, measurement, automation, process automation, industrial automation, genetics, elementary math, etc.

\section{1) Temperature Calibration System}

In the metrology area a temperature calibration system prototype is available at pt.lab2go for demonstrating a standard procedure used in metrological laboratories.

In this case, a platinum resistance (PT100) is connected to a two wire transmitter. All the system is to be submitted to the calibration procedure.

The thermostatic bath is controlled by a PID controlling unit (Polystat CC3) responsible for powering on and off the heating system. This control unit integrates a standard temperature element. A stirrer system is responsible for the water bath temperature uniformity, Fig 3.

The user interface (Fig. 3) is developed in LabVIEW 7.1 and can be remotely actuated. But, several parameters should be established and introduced by the user as, for example, the desired calibration range. The lower limit of the range is naturally imposed by the bath equilibrium at room temperature (visible in the digital display). The upper limit is set by the user and should not exceed a

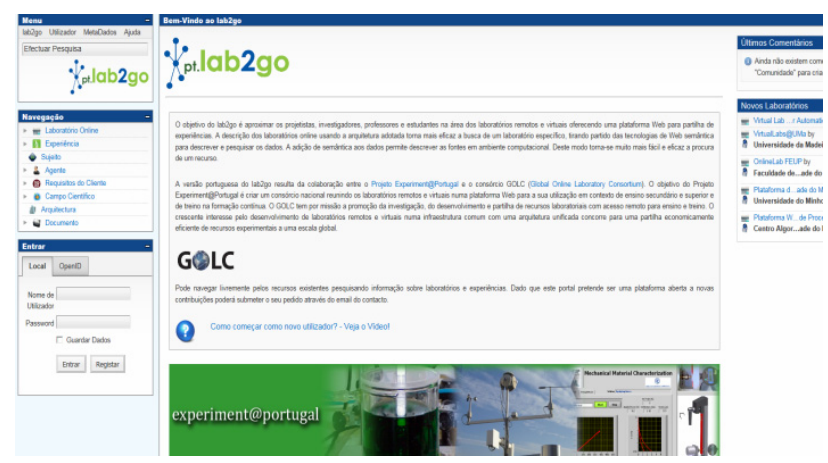

Figure 2. Home page of the pt.lab2go platform. 


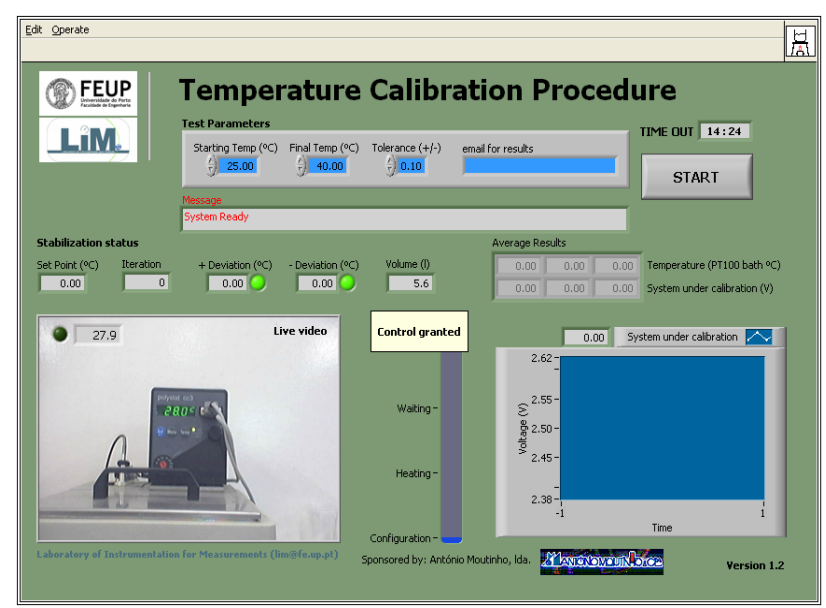

Figure 3. Temperatura calibration procedure remotely accessible: user interface.

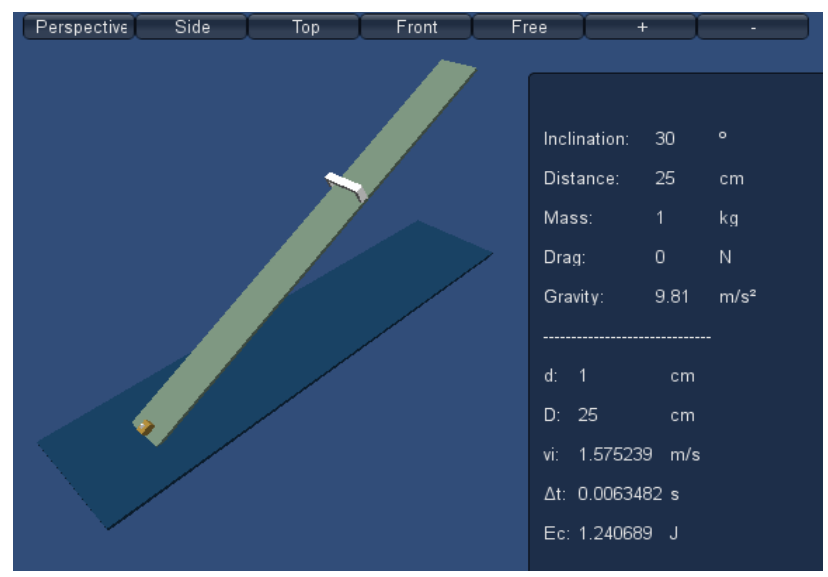

Figure 4. Virtual experiment for demonstration of basic concepts of physics.

security value $\left(90^{\circ} \mathrm{C}\right)$ which, by safety, is limited by the system itself.

After introducing the tolerance interval for establishing a stabilization criterion for each temperature level in the process an automatic standard procedure is followed similarly to those used in metrological labs.

Data is emailed to the user address if it has been introduced before the start of the experience. With emailed data in an Excel format, the user can make several calculations and (s)he should be able to trace the characteristic of that temperature system (sensor + transmitter).

\section{2) Basic concepts of physics}

In several domains, the knowledge of basic concepts of physics is of great importance. The virtual experiment presented in Fig. 4 is available throughout the pt.lab2go platform for understanding the type of motion of an object placed on an inclined plane when it slides down the surface due to an unbalanced force with an acceleration that depends on several factors.

For instance, in the context of classes of secondary schools, to realize this type of motion, it is important to study the forces acting upon an object when it gets down the inclined plane.

This module can be used, firstly, to prepare the laboratorial experiment and, in a second phase, to repeat virtually the experiment, obtaining new data to consolidate the knowledge about the involved physics principles.

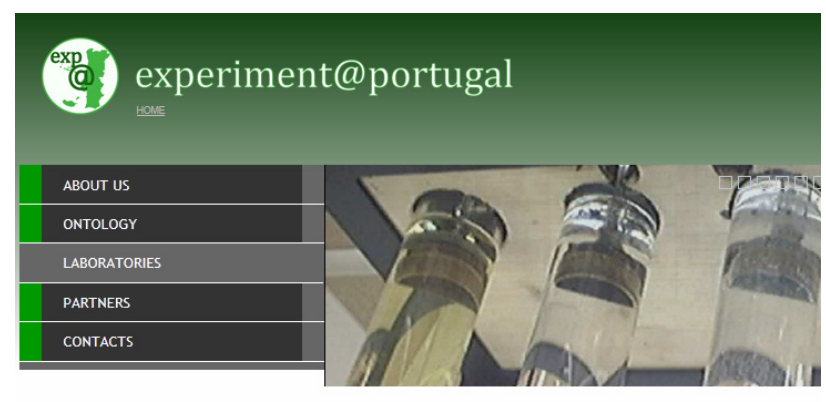

Laboratories

Here it can be found examples of resources applied in the contexts of secondary and higher education and lifelong training Your opinion is very important to us. Please, register it here

Figure 5. Surveys available at the experiment@portugal Web site.

\section{Disseminating The Consortium}

The experiment@portugal Web site (http://www.fe.up. pt/experimentaportugal) aims to disseminate and to promote online experimentation, by offering diversified information and by allowing a quick evaluation of the interest of many of contents of the Consortium pt.lab2go.

The experiment@portugal also contributes for diffusion of concepts, using the international ontology recommended by the Global Online Laboratory Consortium (GOLC) [18].

In addition, experiment@portugal aims to enable and to foster conditions for sharing resources with Portuguese speaking countries (the $5^{\text {th }}$ most spoken language), for improving the collaborative work between higher education institutions, with secondary schools and for sharing resources with industry by contributing for lifelong learning and training. The Web site has also an English version to expand the information of Portuguese resources to the international community and thus to contribute for sharing them in the future.

By integrating a statistic evaluation of online experimentation topics this site offers a huge opportunity for getting new results on what the users think about the site in particular (allowing its constant improvement), and about online experimentation, in general, which will be a great new contribution for the online experimentation community.

For evaluating the Web site interest, satisfaction, quality and efficiency as well as the user interest in the topic, inquiries based in platform Qualtrics are being made available, at "Laboratories" level, Fig. 5, for providing statistic studies, https://feup.eu.qualtrics.com/SE/? SID=SV bNOLoxY58zegxc8.

This functionality is of great interest since it is fundamental to understand the online labs users' perspectives. Therefore, a project which has just been approved for carrying on work on online experimentation, Experiment@Portugal 2012, funded by Calouste Gulbenkian Foundation in continuing the previous project results, will be taking advantage from these results for later decisions.

The experiment@portugal Web site is also an important support for international prominence of the pt.lab2go National Consortium.

In general terms it is possible to synthesize the main goals of the experiment@portugal Web site as: 
- Diffusion of the National Consortium Experiment@Portugal (lingua franca version);

- Dissemination of online experimentation resources (online labs/online experiments) available for:

o Secondary schools;

o Higher education;

o Lifelong learning;

o Training;

o Research support.

- Spreading of concepts associated to online experimentation using bilingual online contents;

- Use of multimedia bilingual contents for spreading the available online experimentation;

- Promotion of teaching/learning activities supported by the use of online experimentation;

- Evaluation of the relevance of online experimentation by including statistics tools in the Web site;

- Bringing together different lab structures and multimedia technologies for disseminating experimental resources;

- Improving cognitive impact of online experiments by stimulating visual perception based in multimedia technologies;

- Provide information structure in order to promote and to clarify online experimentation;

- Use of an appropriate Web design in order to get a simple, intuitive and direct Web navigation;

- Improvement in the instructional process for the available topics;

- Promotion of multicultural teaching/learning processes;

- Contribution for pushing the cooperation with developing countries for sharing experimental resources for education.

For evaluating the diffusion, the induced curiosity and the sample dimensions, the Web site uses a free invisible Web tracker, highly configurable hit counter and real-time detailed Web stats (StatCounter).

Finally, a Facebook page was created (http://www.facebook.com/exp.pt) to be associated to the experiment@portugal Web site. The user can interact with those responsible for the Web site and between them. The user will be up to date with new details from experiment@portugal and s(he) can share contents, taking advantage of one of the strongest Facebook features.

\section{FINAL DISCUSSION}

Seven academic partners are the pt.lab2go Web platform seeds, offering 13 labs and 49 online experiments from very distinct areas, covering physics, mechatronics, electronics, chemistry, automation, industrial automation, elementary math, etc. It is open to any newcomer and the authors look to increase it, hoping to reach the huge community of Portuguese speaking people.

The pt.lab2go experiments are of different types included in remote, virtual and hybrid labs.

The platform also includes simulations, tutorial and media contents being in the last the case animations and videos.
The disseminating portal "experiment@portugal" has been awarded by the International E-Learning Association with an honorable mention in the blended learning category of the 2012 International E-Learning AwardsAcademic Division [21].

At the present, the Consortium enters a promising new phase with the current new one year project, recently supported by Calouste Gulbenkian Foundation.

So, the new project Experiment@Portugal-2012 will be working with the present resources of the pt.lab2go Consortium and will use them for exploring the contents, their validation and dissemination at STEM level and in higher education and at industrial training perspectives.

The interaction will be improved and some different capabilities will be added, like the integration of low cost haptic devices, image and sounds all together, which will increase the remote and the virtual "realism", augmented reality and applications to be used in mobile devices. The collaborative teaching/learning activities will be strengthened by improving the present resources infrastructure or even some of their contents as of multimedia type.

The cooperation with African countries will be also one important goal as well as to promote the industrial collaboration.

\section{ACKNOWLEDGMENT}

The authors wish to thank the Calouste Gulbenkian Foundation for funding the Experiment@Portugal project and for believing in their work and funding the new project Experiment@Portugal-2012, which will make possible to improve the previous results. The authors also acknowledge the support of FCTUC and FEUP.

It is also important to thank all the colleagues collaborating with the project who became part of its open team.

Special thanks are due to all who have been working in all different labs along their existence, creating them and, not less important, to those who still help to keep the experiments running. Many other institutions have been also funding all these resources and all of them deserve special recognition.

Finally, a special thank goes to the support of GOLC in the person of Prof. Michael Auer.

\section{REFERENCES}

[1] C. Samoila, S.G. Cosh and D. Ursutiu (2007), "Competences, Remote Labs and Bologna Process, in Advances on remote laboratories and e-learning experiences”, L.Gomes and J. Garcia-Zubía (eds.), pp. 63-96, University of Deusto, Bilbao, Spain.

[2] M.T. Restivo and A. Cardoso (2012). Guest Editorial, Special Issue: exp.at'11 Conference, International Journal of Online Enginering (iJOE), Vol. 8.

[3] L. Gomes and S. Bogosyan (2009). "Current Trends in Remote Laboratories”, IEEE Transactions on Industrial Electronics, 56(12), pp. 4744-4756. http://dx.doi.org/10.1109/TIE.2009. $\underline{2033293}$

[4] D. Oblinger and J. Oblinger (2005). "Educating the Net Generation Introduction, Transforming education trough information technologies", Educose.

[5] B. Pradarelli, L. Latorre, M-L. Flottes, Y. Bertrand and P. Nouet (2009). "Remote Labs for Industrial IC Testing". IEEE Transactions on Learning Technologies, 2(4), pp. 304-311. http://dx.doi.org/10.1109/TLT.2009.46

[6] P. Xia, A. Lopes and M.T. Restivo (2011). "A New Type Hapticbased Virtual Environment System for Assembly Training of Complex Products". International Journal of Advanced Manufacturing Technology. http://dx.doi.org/10.1007/s00170-011-3381-8 


\section{SPECIAL FOCUS PAPER \\ Promoting REMote AND VIRTUAL LABS IN PORTUGAL}

[7] A. Rojko, A. Pester and K. Jezernik (2011). "International EPRAGMATIC network for adult engineering education”. IEEE Global Engineering Education Conference (EDUCON), Amman, Jordan, pp. 34-39. http://dx.doi.org/10.1109/EDUCON.2011. $\underline{5773109}$

[8] A. Pester, A. Rojko and C. Maier (2011). "Distance training of Mechatronics and Alternative technologies in European industry". International conference on e-learning on workplace, ICELW.

[9] B. Steder, G. Grisetti, M. Van Loock and W. Burgard (2009). "Robust On-line Model-based Object Detection from Range Images”. URL: http://www.informatik.uni-freiburg.de/ grisetti/ pdf/steder09iros.pdf (accessed in November 2012)

[10] European Community, Education and Training. URL: http://ec.europa.eu/education/lifelong-learning-programme/ ict_en.htm (accessed in November 2012).

[11] http://www.geant.net/ (accessed in November 2012).

[12] M. Lombardi (2007). “Authentic Learning for the 21st Century: An Overview. Educause Learning Initiative - advancing learning through IT innovation". URL: http://www.educause.edu/ ELI/AuthenticLearningforthe21stCen/156769, (accessed in November 2012).

[13] I. Titov, O. Smirnova, A. Glotov and A. Golovin (2012). "Remote Laser Laboratory: First Demonstration”. International Journal of Online Engineering (iJOE), 8. http://dx.doi.org/10.3991/ijoe. v8iS1.1891

[14] A. Rojko, A. Pester and K. Jezernik (2011). "International EPRAGMATIC network for adult engineering education”. IEEE Global Engineering Education Conference (EDUCON), Amman, Jordan, pp. 34-39. http://dx.doi.org/10.1109/EDUCON.2011. $\underline{5773109}$
[15] http://www.plastics.ca/EducationalTools/Experiments/index.php (accessed in November 2012).

[16] http://pt.lab2go.net/lab2go/ (accessed in November 2012).

[17] http://www.lab2go.net/ (accessed in November 2012).

[18] http://online-lab.org/ (accessed in November 2012).

[19] M. T. Restivo, J. C. Alves, and A. Cardoso, "Experiment@Portugal”, International Journal of Engineering Pedagogy (iJEP), vol. 1(1), 2011, pp. 46-49.

[20] M. E. Auer, D. G. Zutin, C. Maier and N. Michael. "Lab2go - a Semantic Framework to Exchange and Publish Online Laboratories”, REV 2010, pp. 133-138, Stockholm, Sweden.

[21] IELA Past winners, http://www.ielassoc.org/awards_program/ past_winners.html, October 2012 (accessed in November 2012).

\section{AUTHORS}

M. T. Restivo is with the UISPA, IDMEC-Pólo FEUP and with the Mechanical Department at the Faculdade de Engenharia, Universidade do Porto, Rua Dr. Roberto Frias, 4200-465 Porto, Portugal (trestivo@fe.up.pt).

A. Cardoso is with the CISUC - Centre for Informatics and Systems of the University of Coimbra, Department of Informatics Engineering, University of Coimbra, Polo II, 3030-290 Coimbra, Portugal (alberto@dei.uc.pt).

This work was partially supported by the Experiment@Portugal project, funded by the Calouste Gulbenkian Foundation. It is an extended and modified version of a paper presented at the IGIP2012 conference, held 26 - 28 September 2012, in Villach, Austria. Received 30 November 2012. Published as resubmitted by the authors 28 January 2013. 